Research Paper

\title{
The role of copper transporter ATP7A in platinum-resistance of esophageal squamous cell cancer (ESCC)
}

\author{
Zhuang-hua Li1†, Rongjie Zheng2†, Jing-tang Chen ${ }^{1}$, Jun Jia ${ }^{1}$, Miaozhen Qiu ${ }^{3,4}$ \\ 1. Department of Medical Oncology, Dongguan People's Hospital, Dongguan, Guangdong, 523059, China. \\ 2. Department of Pharmacy, Guangdong No 2. People's hospital, Guangzhou, Guangdong, 510317, China. \\ 3. Department of Medical Oncology, Sun Yat-Sen University Cancer Center; State Key Laboratory of Oncology in South China; Collaborative Innovation \\ Center for Cancer Medicine, Guangzhou, Guangdong 510060, China; \\ 4. Department of Pathology, The Johns Hopkins University School of Medicine, Baltimore, MD 21231, USA \\ † Contributed equally \\ $\square$ Corresponding author: Dr Miaozhen Qiu, MD, PhD. Department of Medical Oncology, Sun Yat-Sen University Can cer Center, 651 Dong Feng Road East, \\ Guangzhou 510060, China; Fax:+86-20-8734 3351; E-mail: qiumzh@sysucc.org.cn
}

( ) Ivyspring International Publisher. Reproduction is permitted for personal, noncommercial use, provided that the article is in whole, unmodified, and properly cited. See http://ivyspring.com/terms for terms and conditions.

Received: 2016.05.09; Accepted: 2016.08.14; Published: 2016.10.23

\begin{abstract}
Purpose: Platinum derivatives, such as cisplatin (DDP), carboplatin and oxaliplatin, are widely used components of modern cancer chemotherapy including esophageal squamous cell cancer (ESCC). However, their roles are limited by the impact of intrinsic/acquired resistance mechanisms on tumor responses. Recent studies have shown that the mammalian copper transporters CTR1, ATP7A and ATP7B are involved in cisplatin-resistance to some cancers.

Methods: The cytotoxicities of DDP in different cell lines were determined using the MTT assay. To determine whether knockdown the expression of ATP7A could reverse the platinum-resistance of EC109/DDP cells or not, we used RNA interference system to explore the role of ATP7A in platinum resistance.

Results: We found that DDP-resistant cell sublines EC109/DDP (8.490 folds) showed cross-resistance to carboplatin (5.27 folds) and oxaliplatin (4.12 folds). ATP7A expressions in DDP-resistant cell sublines (EC109/DDP) were much higher than DDP-sensitive cell lines (EC109) at both mRNA and protein levels. ATP7A targeted small interfering RNA duplex at 100nM final concentration added into DDP-resistant cancer cells (EC109/DDP) markedly inhibited the expression of ATP7A as determined by Western blot (83.0\%) and partially reversed DDP-resistance (37.09\%), moreover, it also increased cell apoptosis at different DDP concentrations. Conclusions: These findings indicate that ATP7A high expression plays an important role in platinum-resistance of ESCC. This study sheds light on platinum resistance in ESCC patients and may have implications for therapeutic reversal of drug resistance.
\end{abstract}

Key words: ATP7A, Esophageal squamous cell cancer, Platinum, Resistance

\section{Introduction}

Esophageal cancer is the $6^{\text {th }}$ most common cause of cancer deaths worldwide (1) and it is an endemic in many parts of the world, particularly in the developing countries, including China (2, 3). Histologically, esophageal cancer can be classified as adenocarcinoma and esophageal squamous cell carcinoma (ESCC) which is the most common histology in Asia (4). For locally advanced or metastatic ESCC patients, chemotherapy can improve overall survival (OS) and progression free survival (PFS) (5). Cisplatin (DDP) is one of the most active agents with a single-agent response rate of about $20 \%$ 
(6). One of the most important problems in the treatment of ESCC is the intrinsic/acquired resistance to platinum derivatives (DDP, CBDCA and L-OHP) (7). Knowledge of the active mechanism of resistance may lead to new treatment strategies by overcoming platinum-resistance and by selection of platinum-resistance patients for specific treatment modalities, then improve OS of patients with ESCC.

In vitro, the major mechanisms of resistance to platinum include decreased drug accumulation, enhanced detoxification, and increased DNA repair efficiency (8-10). Among these, reduced cellular drug accumulation is the most universally identified mechanism of acquired platinum resistance (11-13). Multidrug resistance (MDR) has been noted as an important mechanism of drug resistance in tumor cell lines. ATP binding cassette transporters are implicated in MDR phenotypes of tumor cells (14) and can reduce cellular drug accumulation. MDR1 gene encodes for $\mathrm{P}$ glycoprotein (P-gp), which plays an important role in the bioavailability and cell-toxicity limitation of a wide range of drugs and xenobiotics (15). The multidrug resistance-associated protein 1 (MRP1, or $A B C C 1)$, lung resistance protein (LRP, or MVP), the ATP-binding cassette, sub-family G member 2 protein (ABCG2, or BCRP) were association with the multidrug-resistance in the ESCC cell lines (16). Increasing cytoplasmic constituents, including the abundant nucleophilic GSH catalyzed by GSH-S-transferase (GST) and the cysteine-rich metallothionein enhanced platinum's detoxification and induced platinum resistance. Qiang, F (17) reported that the design and application of chemotherapeutic protocols capable of reducing GST-pi expression might be beneficial for patients with ESCC. In addition, increased DNA repair is another factor that might confer platinum resistance, such as DNA polymerase beta (DNA pol $\beta$ ) could bypass other DNA damage adducts in vitro, including platinum-induced intra-strand adducts (18).

As an essential trace element and catalytic factor for many enzymes, copper plays an important role in human physiology and metabolism. Its homeostasis is tightly regulated by many factors including copper uptake, intracellular distribution, and copper export. The three processes are mediated through the coordinated action of the copper uptake protein Ctr1, the copper export proteins ATP7A and ATP7B. Recent reports showed that import and export copper transporters were also involved in the transport of platinums. Cells selected for DDP-resistance are cross-resistant to $\mathrm{Cu}$, and vice versa (19). Ctr1 has been convincingly demonstrated to transport cisplatin and its analogues, such as carboplatin and oxaliplatin. Yeast, mouse and human cells lacking Ctr1 display decreased cisplatin accumulation and increased cisplatin resistance $(20,21)$. Evidences also suggest that the two copper efflux transporters ATP7A and ATP7B regulate the efflux of DDP $(12,22)$. Recently, we found that ATP7A was associated with platinum-resistance in non-small cell lung cancer (NSCLC) (22). ATP7B, another copper efflux transporter, has also implicated in platinum-resistance $(23,24)$.

Whether ESCC cells share common drug resistance mechanisms with other cancers or possess their own distinct characteristics is still in doubt. Hence, knowledge of the active mechanism of platinum resistance in ESCC may lead to new treatment strategies and allow the selection of patients for specific treatment modalities

\section{Materials and Methods}

\section{Drugs}

DDP and CBDCA were purchased from Bristol-Myers Squibb (NY, USA), and L-OHP was provided by Sanofi-aventis (Paris, France). DDP was stored as a $3.3 \mathrm{mM}$ stock solution in $0.9 \% \mathrm{NaCl}$ in the dark at room temperature, CBDCA was stored as a 27 $\mathrm{mM}$ stock solution in water at $4^{\circ} \mathrm{C}$, and L-OHP was stored as a $12.6 \mathrm{mM}$ stock solution in water at $-20^{\circ} \mathrm{C}$.

\section{Cell lines and cell culture}

Esophageal squamous cell cancer (ESCC) cell line EC109 and its DDP-resistant subline EC109/DDP were all cultured in the Dulbecco's modified Eagle's medium (DMEM) (Invitrogen, CA, USA) supplemented with $10 \%$ fetal bovine serum (Invitrogen, CA, USA), $100 \mathrm{U} / \mathrm{ml}$ penicillin (Tianxin, Guangzhou, China) and $100 \mathrm{U} / \mathrm{ml}$ streptomycin (Merro,Dalian, China) in a humidified incubator containing $5 \% \mathrm{CO} 2$ at $37^{\circ} \mathrm{C}$.

\section{MTT assay}

The cytotoxicities of DDP, CBDCA and L-OHP were determined using the MTT assay. Monodispersed cells in the exponential growth phase were plated in $200 \mu \mathrm{l}$ of medium per well in 96-well plates. After overnight incubation, medium without drug was added to the control and blank wells, and medium in other wells was removed and replaced by various concentrations of the drugs mentioned above. Eight different concentrations for each drug were analyzed, and three wells were used for each determination. After a 72 hour- incubation, $20 \mathrm{ul}$ of MTT $(5 \mathrm{mg} / \mathrm{ml}$ phosphate-buffered saline) was added to each well and incubated for an additional $4 \mathrm{~h}$. After aspiration of the culture medium, the resulting formazan was dissolved with 100 ul of dimethylsulfoxide (DMSO). After shaking for $10 \mathrm{~min}$, 
96-well plates were read at 570 and $630 \mathrm{~nm}$ using an enzyme-linked immunosorbent assay reader (Thermo Labsystems, Franklin, Massachusetts, USA). According to these results, the dose-response curve could be plotted, from which the inhibitory concentration that killed $50 \%$ of cell population (IC50) was derived. Resistance index (RI) was calculated as IC50 resistant / IC50 sensitive cell line. Experiments were performed in triplicate.

\section{Semi-quantitative RT-PCR}

The mRNA expression of multidrug resistance-related genes, MDR, MRP1, ABCG2, LRP, GST-pi, DNApolßand copper transporters (CTR1, ATP7A and ATP7B) were determined using semi-quantitative RT-PCR. Total RNA was isolated from EC109, EC109/DDP cells using Trizol reagent (Invitrogen, CA, USA) according to the manufacturer's instructions. RNA was quantified spectrophotometrically by Nucleic Acid/Protein Analyzer DU 800 (Beckman Coulter, CA, USA). Total RNA was reverse-transcribed using the First Strand cDNA Synthesis Kit (Promega, WI, USA). $15 \mu \mathrm{l}$ reaction volume containing $2 \mu \mathrm{g}$ RNA and $1 \mu \mathrm{l}$ oligo
(dT) ${ }_{15}$ Primer was denatured at $70^{\circ} \mathrm{C}$ for $5 \mathrm{~min}$ and then quickly chilled on ice. To synthesize cDNA, a reaction mixture was added to the denatured RNA so that the final $25 \mu \mathrm{l}$ reaction volume containing $5 \mu \mathrm{l}$ $5 \times \mathrm{RT}$ Buffer (containing 25mM Mg2+), $1 \mu \mathrm{l}$ RNase Inhibitor $(10 \mathrm{U} / \mu \mathrm{l}), 1 \mu \mathrm{l}$ Moloney murine leukemia virus reverse transcriptase $(100 \mathrm{U} / \mu \mathrm{l})$, and $1 \mu \mathrm{dNTP}$ mixture (each $10 \mathrm{mM}$ ). The reaction was incubated at $37^{\circ} \mathrm{C} 60 \mathrm{~min}$. Then cDNA $(2 \mu \mathrm{l})$ was then amplified by PCR using $12.5 \mu \mathrm{l} 2 \times$ GoTaq Green Master Mix (Promega, WI, USA), $2.5 \mu \mathrm{l}$ upstream primers, $2.5 \mu \mathrm{l}$ downstream primer (10 mM for each primer) and 5.5 $\mu l$ Nuclease-Free Water with the total volume of $25 \mu \mathrm{l}$. The primers were synthesized according to previous reports [26; 27; 28; 29] or designed using the Primer Express ${ }^{\circledR}$ program (Applied Biosystems). The primers sequences, gene bank accession number, annealing temperature and length of products were listed in table 1. GAPDH was used as an internal control. Aliquots of PCR product were electrophoresed on $1.5 \%$ agarose gels, and PCR fragments were visualized by ethidium bromide staining.

Table 1. Primers used for RT-PCR analysis.

\begin{tabular}{|c|c|c|c|c|}
\hline Gene & Primers $\left(5^{\prime} \rightarrow 3^{\prime}\right)$ & Gene bank accession number & Annealing Temperature $\left({ }^{\circ} \mathrm{C}\right)$ & Size $(b p)$ \\
\hline MDR1 & & NM_000927.3 & 58 & 154 \\
\hline forward & ATATCAGCAGCCCACATCAT & & & \\
\hline reverse & GAAGCACTGGGATGTCCGGT & & & \\
\hline MRP1 & & NM_019898.2 & 60 & 181 \\
\hline forward & ATCAAGACCGCTGTCATTGG & & & \\
\hline reverse & GAGCAAGGATGACTTGCAGG & & & \\
\hline ABCG2 & & NM_004827.2 & 60 & 172 \\
\hline forward & TGCCCAGGACTCAATGCAACAG & & & \\
\hline reverse & ACAATTTCAGGTAGGCAATTGTG & & & \\
\hline LRP & & NM_017458.2 & 53 & 240 \\
\hline forward & GTCTTCGGGCCTGAGCTGGTGTCG & & & \\
\hline reverse & CTTGGCCGTCTCTTGGGGGTCCTT & & & \\
\hline GST pi & & NM_000852.3 & 46.5 & 399 \\
\hline forward & СCTACACCGTGGTCTATTTC & & & \\
\hline reverse & GGGACAGCAGGGTCTCAA & & & \\
\hline DNA pol $\beta$ & & NM_002690.1 & 42 & 139 \\
\hline forward & TGCCTGGAGTAGGAACA & & & \\
\hline reverse & GGACCAATGCCACTAAC & & & \\
\hline CTR1 & & NM_001859.3 & 54 & 445 \\
\hline forward & AGCTATATGGACTCCAACAG & & & \\
\hline reverse & CGTTGTAGGTCATGAAGATG & & & \\
\hline ATP7A & & NM_000052.4 & 54 & 175 \\
\hline forward & GCCTGCGTACGTGGATTTAT & & & \\
\hline reverse & TCAATGGTCCAAACACAGGA & & & \\
\hline АТР7В & & NM_000053.2 & 42 & 407 \\
\hline forward & GGGGTGTAGGTTCTCGC & & & \\
\hline reverse & TGCTCCCAAAGGGTTCT & & & \\
\hline GAPDH & & NM_002046.3 & 50 & 358 \\
\hline forward & CGGGAAGCTTGTCATCAATGG & & & \\
\hline reverse & GGCAGTGATGGCATGGACTG & & & \\
\hline
\end{tabular}




\section{Immunoblotting}

Whole-cell extracts were obtained by lysis of cells in a $2 \times$ sodium dodecyl sulfate (SDS)-polyacrylamide gel electrophoresis sample buffer. Equal amounts of protein $(50 \mathrm{mg} / \mathrm{sample}$ as determined by UV spectrometry) were electrophoresed on 10\% SDS-PAGE gels and transferred to polyvinylidene difluoride (PVDF) membranes in 25mmol/1 Tris- $\mathrm{HCl}(\mathrm{pH} \mathrm{8.3)}$ for $2 \mathrm{~h}$ at $100 \mathrm{~mA}$.The membranes were blocked with Tween Tris-buffered saline (TBS) with 5\% nonfat milk and $0.1 \%$ Triton X-100 for 2 hours at room temperature and reacted with primary antibodies overnight at $4^{\circ} \mathrm{C}$. Primary antibodies were diluted in a blocking solution 1: 500 for ATP7A (Abcam, Cambrige, UK) and 1 : 5000 for GAPDH (Boster, Wuhan, China). After washing with TBS Tween-20 for 30min, membranes were incubated with horseradish peroxidase-conjugated secondary antibodies at room temperature for $1 \mathrm{~h}$, then washed for $1 \mathrm{~h}$ with TBS Tween-20. Bands were developed using chemiluminescent detection reagents and signal detection and quantification were carried out with an ECL system (Amersham Biosciences, New Jersey, USA) and Image Quant analysis software Quantity One V4.62 (Bio-Rad, CA, USA).

\section{siRNA transfection}

ATP7A siRNA sequences were obtained from Ambion (Austin, TX) siRNA library (ID number 120175) and targeted exon 11 (sense, GCAACUAUUGUAACUCUUG dTdT; antisense, CAAGAGUUACAAUAGUUGC dTdT) [30]. A nonsilencing siRNA sequence, shown by BLAST search to not share sequence homology with any known human mRNA was used as control for ATP7A-targeting experiments. The siRNA sequences were synthesized by Guangzhou RiboBio (Ghuangzhou, China). EC109/DDP or A549/DDP cells were plated into 6-well plates as required for the experiments. The cells were allowed to adhere for overnight. The transfection of siRNA was performed using lipofectamine-2000 (Invitrogen, CA, USA) according to the manufacturer's recommendation. Oligofectamine / siRNA complexes were formed in serum free DMEM by adding siRNA $(25,50$ or $100 \mathrm{nM}$ final concentration) to $5 \mu \mathrm{l}$ of Oligofectamine (Invitrogen, CA, USA) per well. Complexes were allowed to form at $25^{\circ} \mathrm{C}$ for $10 \mathrm{~min}$ and added to wells (500 $\mu$ l per well). After 4 hours of transfection, the culture medium containing $10 \%$ serum was added. The assays were carried out $24,48,72,80$ hours post transfection.

\section{Flow cytometry}

Apoptotic or necrotic cell death was determined by flow cytometric analysis of cells double stained with Annexin V-FITC and propidium iodide (PI) using an assay kit from KeyGen Biotech (Nanjing, China). EC109/DDP cells were plated into 6-well plates and adhered for overnight. Then $100 \mathrm{nM}$ final concentration of siRNA (targeted-ATP7A or nonsilencing siRNA) was added to wells for transfection. After 4 hours of transfection and 72 hours for DDP incubation, cells were collected, washed with cold PBS, and suspended in binding buffer. The cells were stained with Annexin V-FITC and PI for 15 minutes at room temperature in the dark. The samples were analyzed with a flow cytometer (BECKMAN-COULTER FC500, CA, USA).

\section{Results}

\section{Drug sensitivities to platinum-derivatives}

The drug sensitivity data of EC109 and EC109/DDP cells to three platinum-derivate drugs (DDP, CBDCA and L-OHP) was shown in Table 2. The IC50 ranged from 2.84 to $24.13 \mathrm{uM}$ for DDP, from 16.35 to 86.08 for CBDCA, and 7.11 to 29.29 for L-OHP. Compared with the parental cells, the DDP-resistant sublines (EC109/DDP) showed 8.49, 5.27 and 4.12 folds enhanced resistance to DDP, CBDCA, and L-OHP respectively.

Table 2. Drug sensitivity of EC109 and EC109/CDDP cells to platinum derivatives (CDDP, CBDCA and L-OHP).

\begin{tabular}{lllll}
\hline \multicolumn{7}{l}{ IC50 $($ mean \pm SD, $\mathbf{u M})$} & & \\
\hline Drugs & EC109 & EC109/DDP & RI & P \\
\hline DDP & $2.84 \pm 0.10$ & $24.13 \pm 1.47$ & 8.49 & $<0.001$ \\
CBDCA & $16.35 \pm 0.49$ & $86.08 \pm 1.88$ & 5.27 & $<0.001$ \\
L-OHP & $7.11 \pm 0.49$ & $29.29 \pm 1.20$ & 4.12 & $<0.001$ \\
\hline
\end{tabular}

\section{Expression of drug resistance-related genes}

Gene expression analysis of MDR1, ABCG2, MRP1, LRP, DNApol $\beta$, GST-pi, CTR1, ATP7A and ATP7B in mRNA were shown in Figure 1a. After normalizing the mRNA expression level of each gene relative to GAPDH expression, we compared the expressions of drug resistance-related genes in resistant sublines (EC109) to their drug-sensitively parental cell lines (EC109/DDP) respectively. Between EC109 and EC109/DDP cells, there was no difference in the expression of ABCG2, MRP1, LRP, DNApol $\beta$, GST-pi, CTR1 and ATP7B, but ATP7A mRNA expressions in EC109/DDP cell was significantly higher than in the parental cells. Surprisingly, MDR1 mRNA expression was significantly lower in EC109/DDP cells as compared to EC109 cells. Using RT-PCR, we found that copper 
transporter ATP7A mRNA expressions in EC109/DDP cells was much higher than in EC109 cells. Furthermore, we analyzed the ATP7A protein expression in these two kinds of cells with Western-Blot (Figure 1b). After normalizing the protein expression level of ATP7A relative to GAPDH, ATP7A protein expression was much higher in EC109/DDP than in EC109 cells (Supplementary figure 1). These results indicated that ATP7A may be related to the platinum-derivates resistance in EC109/DDP cells.

\section{SiRNA targeting ATP7A decreases the expressions of ATP7A protein in DDP-resistant cancer cells}

To determine whether or not knockdown the expression of ATP7A could reverse the platinum-resistance of EC109/DDP cells, we used RNA interference system to explore the role of ATP7A in platinum resistance. As shown in Figure 2, ATP7A expressions in EC109/DDP cells changed after treatment with different final concentration of ATP7A-targeted siRNA sequences $(25 \mathrm{nM}, 50 \mathrm{nM}$ and 100nM) for 80h. $25 \mathrm{nM}$ ATP7A-targeted siRNA sequences have no effects on the expressions of ATP7A protein in the DDP-resistant cancer cells, and 50nM ATP7A-targeted siRNA sequences partially knockdown the expressions of ATP7A protein in EC109/DDP cells. In the treatment of $100 \mathrm{nM}$ ATP7A-targeted siRNA sequences, the expressions of ATP7A protein in EC109/DDP cells were almost silenced $(83.0 \%)$. The expression of control protein,
GAPDH, was unaffected by ATP7A-targeted siRNA treatment. $100 \mathrm{nM}$ nonsilencing siRNA sequence as control siRNA had absolutely no effect on the levels of ATP7A or GAPDH in EC109/DDP cells. Based on the results, 100nM ATP7A-targeted siRNA sequences were enough and specific to remarkably decrease the expression of ATP7A protein in EC109/DDP cells.

\section{Effect of RNAi targeting ATP7A on chemosensitivity to DDP in EC109/DDP cells}

EC109/DDP cells were transiently transfected with ATP7A-targeted siRNA $100 \mathrm{nM}$ for $8 \mathrm{~h}$, then cells were exposed to DDP for another $72 \mathrm{~h}$. MTT assay was employed to investigate the reversal effect of siRNA transfection $(100 \mathrm{nM}, 80 \mathrm{~h})$ on the DDP-resistance of EC109/DDP cells. The results were shown in Table 3. Experimental data showed that siRNA transfection targeting ATP7A significantly reduced IC50 of EC109/DDP cells compared with controls (reversal effect of 37.09\%). Silencing ATPA was able to partially reverse DDP-resistance in EC109/DDP cells. These results indicated that ATP7A played an important role in the modulation of platinum-resistance in EC109/DDP cells.

Table 3. Partially reversal effect after ATP7A's silence by siRNA for $80 \mathrm{~h}$ in the DDP-resistant sublines (EC109/DDP).

\begin{tabular}{llll}
\hline cell lines & $\mathrm{IC}_{50}($ mean $\pm \mathrm{SD}, \mathrm{uM})$ & reversal effect $(\%)$ & $\mathbf{P}$ \\
\hline $\begin{array}{l}\text { EC109/DDP } \\
\text { Control SiRNA }\end{array}$ & $24.10 \pm 1.01$ & & \\
EC109/DDP & $15.16 \pm 0.24$ & 37.09 & $<0.001$ \\
ATP7A SiRNA & & &
\end{tabular}
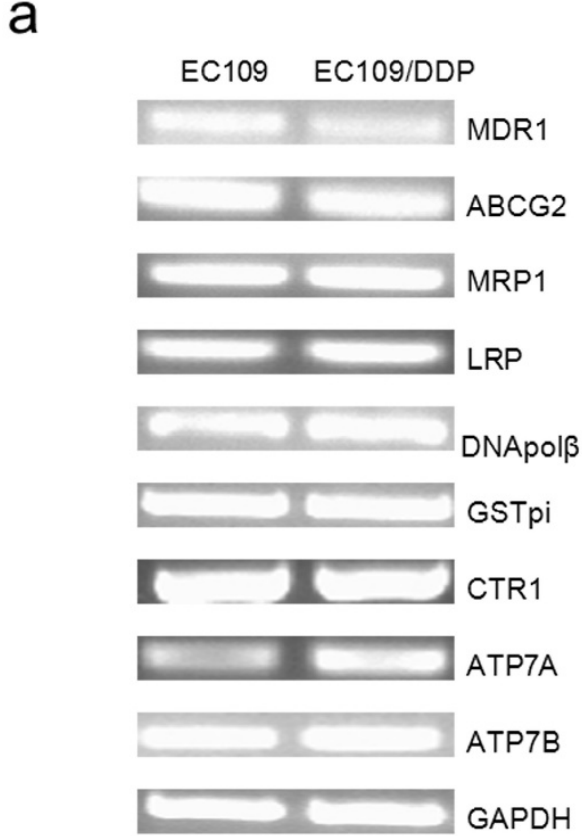

b

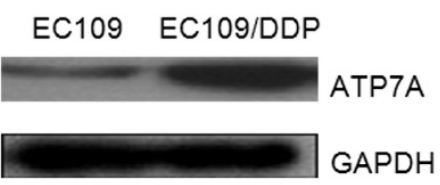

Figure 1. Expression of drug resistance-related genes (MDR1, ABCG2, ABCC1, LRP, DNA polß, GSTpi, CTR1, ATP7A and ATP7B) in EC109 and EC109/DDP. a). Total RNA isolated from EC109 and EC109/DDP cells was subjected to RT-PCR for the indicated nuclear genes, as described in Materials and Methods. Reaction products were analyzed on an agarose gel and visualized by ethidium staining. b). ATP7A protein expression was determined by Western blot analysis using anti-ATP7A antibody. 
EC1099/DDP siRNA

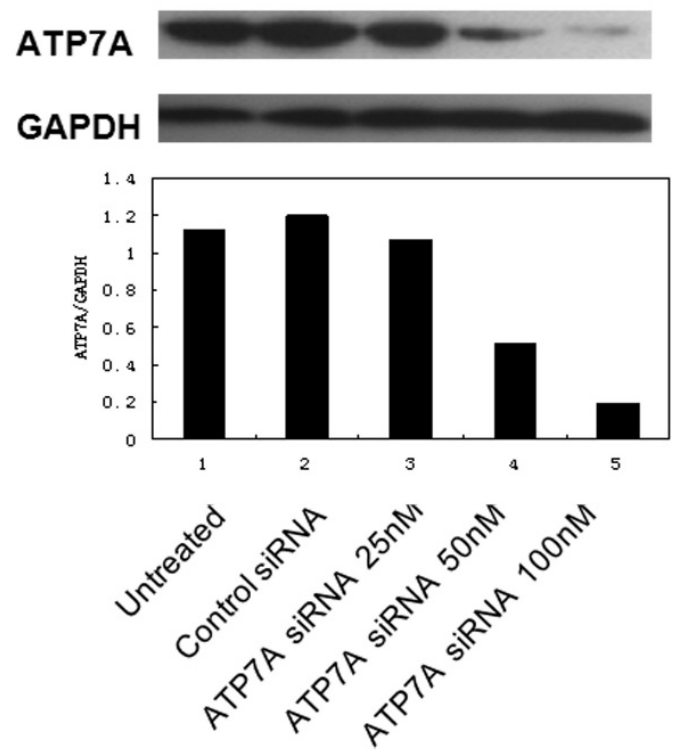

Figure 2. Effect of ATP7A-siRNA 80h on ATP7A's protein expression in DDP-resistant cell sublines (EC109/DDP).

\section{RNAi targeting ATP7A increased apoptotic rate in EC109/DDP}

To further determine whether ATP7A-targeted siRNA transfection could effectively reverse the platinum-resistance of EC109/DDP, DDP-induced apoptosis was detected and shown as Figure 3. Without DDP, there were little apoptosis and no significant difference between ATP7A-targeted siRNA groups and control siRNA groups in all cells. But after adding different concentrations of DDP for 72h, ATP7A-targeted siRNA groups' cells apoptotic rates were significantly higher than control siRNA groups $(39.0 \pm 2.17 \%$ VS $17.2 \pm 1.40 \%$ at $25 \mathrm{uM}$ DDP and $62.1 \pm 1.76 \%$ VS $44.4 \pm 2.01 \%$ at $50 \mathrm{uM}$ DDP). So siRNA transfection targeting ATP7A significantly enhanced DDP-inducing apoptosis compared with siRNA-control at different DDP concentrations $(\mathrm{P}<$ 0.01 ). These results showed the potential mechanism of ATP7A in the modulation of platinum resistance.
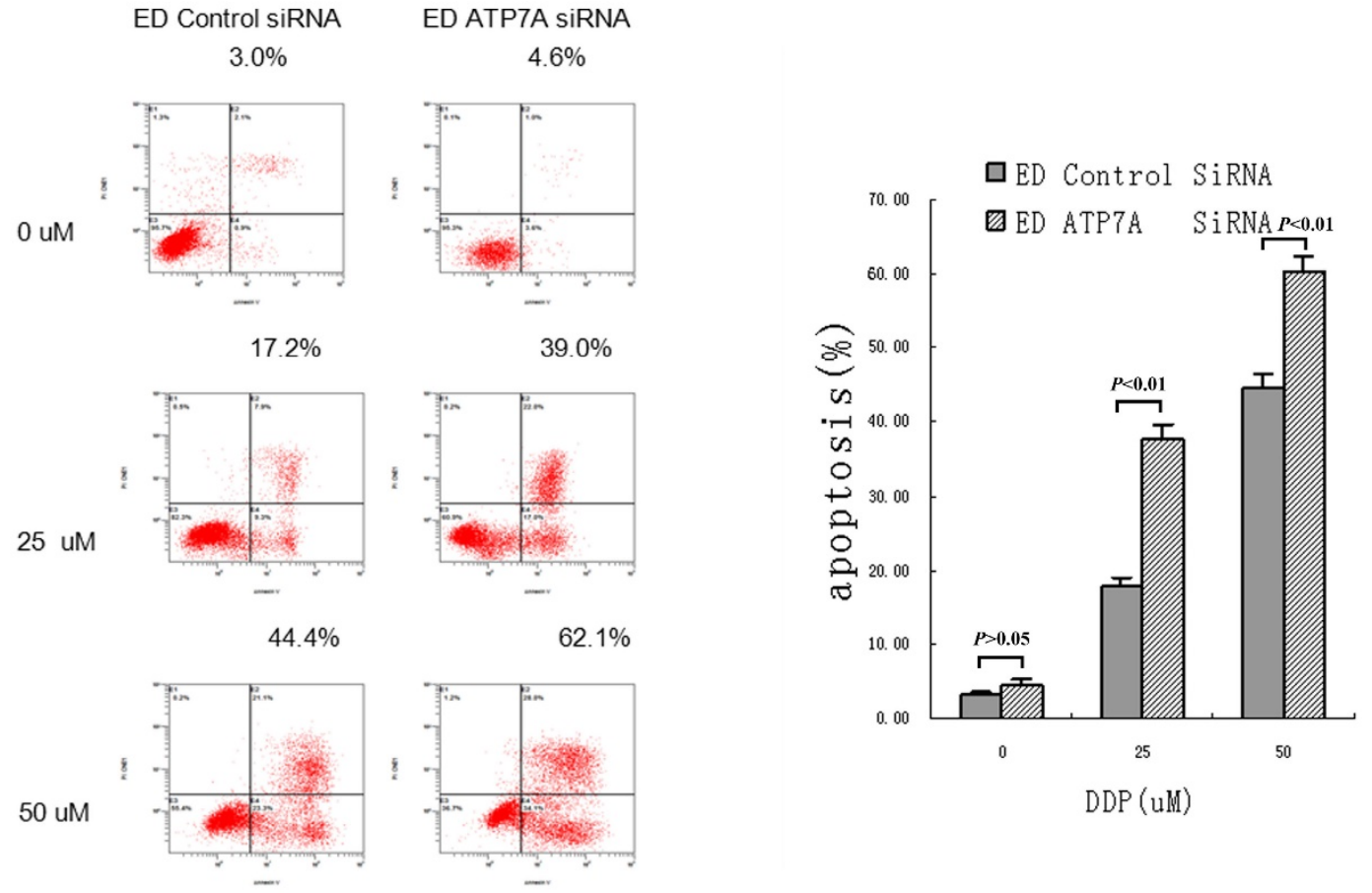

Figure 3. Increasing DDP induced apoptosis after ATP7A's silence for $80 \mathrm{~h}$ by siRNA in A549/DDP cells.

\section{Discussion}

This article sheds light on the potential cellular functions of copper transporter ATP7A for platinum-resistance in ESCC.

In our study, DDP-resistant cell sublines (EC109/DDP) are 8.49 folds resistant to DDP than the parental cells (EC109 lines), and both exhibit cross-resistance to CBDCA (5.27 folds) and L-OHP (4.12 folds), to which they were not previously exposed, indicating they were multidrug-resistant cell lines.

Although the mRNA expression of ABCG2, MRP1, LRP, GST-pi, CTR1, and ATP7B between 
EC109/DDP and EC109 cells was similar, MDR1 expression significantly decreased in EC109/DDP cells compared with EC109 cells which was consistent with the result reported by Wen J (16), who established the EC109/DDP subline. It seemed that the mechanisms of platinum resistance in EC109/DDP cells might be independent of ABC transporters. Previous reports showed that increased drug efflux and lowered intracellular drug concentration both contributed to MDR, in which ATP-binding cassette $(\mathrm{ABC})$ transporters including MDR1, MRP1, and ABCG2 and LRP (25) were the most prominent. But in general, platinum drugs are not transported by $\mathrm{ABCB} 1, \mathrm{ABCC} 1$ or $\mathrm{ABCG} 2(26,27)$. But mRNA did not always parallel with protein expression or activity. Protein level and/or activity of ABC transporters, but not mRNA level may determine drug resistance.

We found that ATP7A expression in both mRNA and protein levels significantly increased in EC109/DDP cells compared to the parental cells respectively. Moreover, in EC109/DDP cells, ATP7A siRNA knockdown $(83.0 \%)$ was able to partially reverse DDP-resistance (37.09\%). As the cytotoxicity of platinum compounds was thought to be determined primarily by their DNA adducts, which could then induce cells apoptosis. In our study, silencing of ATP7A increased cells apoptosis rate in EC109/DDP, so reduced expression of ATP7A by siRNA knockdown resulted in enhancement of DDP-sensitivity and increased DDP-induced apoptosis. These results indicated that ATP7A played an important role in the modulation of platinum resistance in EC109/DDP cells. Overexpression of ATP7A in EC109/DDP cells might increase pumping platinum out of cells or binding and sequestration of platinum drugs, then decrease cellular platinum concentration or keep them away from accessing their key cytotoxic targets in the nucleus, finally result in DDP-resistance $(28,29)$.

Recent studies showed that import and export copper transporters were also involved in platinum-resistance in some cancers $(28,30)$. As a catalytic factor for many enzymes, copper stimulates the proliferation and migration of endothelial cells and is required for the secretion of several angiogenic factors by tumor cells, such as VEGF, therefore it plays an important role in angiogenesis. Thus, silencing the copper transporters resulting in copper level change which may have an additional benefit to reduce angiogenesis (12). Some studies have demonstrated that transporters controlling copper influx, especially Ctr1, are involved in the cellular uptake of DDP (31). Holzer et al. (31) reported that knock-out of Ctr1 in murine embryonic fibroblasts led to reduced uptake of DDP, CBDCA and to a lesser extent of L-OHP. And there have been few reports about copper transporters CTR1 in the small cell lung cancers (SCLC) for the DDP and CBDCA resistance (21). Using Confocal microscopic analysis, Katano, K et al also found ATP7B mediated resistance to DDP by sequestering it into vesicles of the secretory pathway for export from the resistant ovarian cell lines $(32,33)$. ATP7A is overexpressed in some DDP-resistant ovarian carcinoma cell lines (34), and Samimi G also demonstrated that Human ovarian carcinoma cells transfected with an ATP7A-expression construct also conferred resistance to DDP, CBDCA, and L-OHP by sequestering platinum analogues in intracellular compartments and preventing their reaction with nuclear DNA $(10,35)$. Plasencia, C also reported that ATP7A was overexpressed in the L-OHP resistant colorectal cancer cells (36), and Kitada, N demonstrated that ATP7A mRNA was a factor affecting the cytotoxicity of cisplatin and oxaliplatin (37). Our previous study had found that overexpression of ATP7A played an important role in platinum-resistance of NSCLC, and was a negative prognostic factor of NSCLC patients treated with platinum-based chemotherapy (30). But Mangala, LS reported that silencing of ATP7A gene had no significant effect on the sensitivity of resistant cells to DDP, while ATP7B silencing resulted in partial enhancement of DDP-sensitivity and increased DNA adduct formation in cisplatin-resistant ovarian cells (38). But there are no reports about the copper transports in the ESCC patients. As we known, this is the first time study to analyze copper transporters in ESCC cell lines.

Drug resistance is a multi-factorial problem. In our study, efficient down-regulation of ATP7A in EC109/DDP cells could not reverse DDP-resistance completely, indicating that there could be some other important mechanisms accounting for the drug resistant phenotype. Furthermore, the interaction between ATP7A and platinum remains unknown. Does ATP7A transfer intracellular platinum into the vesicular secretory pathway for exporting from the cell, or sequestrating platinum from its targets as one of the components in the cellular platinum detoxification mechanism? Of note, most of these data are derived from in vitro drug-exposed tumor cells while the resistance mechanisms in patients are by far less well understood.

In conclusion, as first evidence, our results collectively indicate that overexpression of copper efflux transporter ATP7A is responsible for platinum resistance in EC109/DDP cells. These studies may ultimately lead to a better utilization of platinum-based antitumor agents and thereby 
improve the chemotherapeutic efficacy in ESCC patients.

\section{Supplementary Material}

Supplementary figure 1.

http://www.jcancer.org/v07p2085s1.pdf

\section{Acknowledgments}

This work was supported by National Natural Science Foundation of China (Grant number. 81602066), Fundamental Research Funds for the Central Universities (Grant number. 16ykpy25); the third outstanding young talents training plan of Sun Yat-sen University cancer center; Scientific and Technological projects Guangdong Esophageal Cancer Institute, China (Grant number. Q201408); China Scholarship Council (Grant number. 201406385034); Science and Technology Planning Project of Guangdong Province, China (Grant number. 2013A022100023); Natural Science Foundation of Guangdong Province, China (Grant number.2014A030312015).

We thank Jing Wen (Department of Thoracic Oncology, Cancer Center, Sun Yat-Sen University, State Key Laboratory of Oncology in Southern China) for the EC109 and EC109/DDP cell lines and helpful discussions.

\section{Competing Interests}

The authors have declared that no competing interest exists.

\section{References}

1. Jemal A, Bray F, Center MM, Ferlay J, Ward E, Forman D. Global cancer statistics. CA Cancer J Clin. 2011; 61: 69-90.

2. Chen W, Zheng R, Baade PD, et al. Cancer statistics in China, 2015. CA Cancer J Clin. 2016; 66: 115-32.

3. Chen $\mathrm{W}$, Zheng $\mathrm{R}$, Zeng $\mathrm{H}$, Zhang $\mathrm{S}$. The updated incidences and mortalities of major cancers in China, 2011. Chin J Cancer. 2015; 34: 502-7.

4. Siewert JR, Ott K. Are squamous and adenocarcinomas of the esophagus the same disease? Semin Radiat Oncol. 2007; 17: 38-44.

5. Boonstra JJ, Kok TC, Wijnhoven BP, et al. Chemotherapy followed by surgery versus surgery alone in patients with resectable oesophageal squamous cell carcinoma: long-term results of a randomized controlled trial. BMC Cancer. 2011; 11: 181.

6. Leichman L, Berry BT. Experience with cisplatin in treatment regimens for esophageal cancer. Semin Oncol. 1991; 18: 64-72.

7. Katoh R, Takebayashi Y, Takenoshita S. Expression of copper-transporting P-type adenosine triphosphatase (ATP7B) as a chemoresistance marker in human solid carcinomas. Ann Thorac Cardiovasc Surg. 2005; 11: 143-5.

8. Amable L. Cisplatin resistance and opportunities for precision medicine. Pharmacol Res. 2016; 106: 27-36.

9. Martin LP, Hamilton TC, Schilder RJ. Platinum resistance: the role of DNA repair pathways. Clin Cancer Res. 2008; 14: 1291-5.

10. Samimi G, Varki NM, Wilczynski S, Safaei R, Alberts DS, Howell SB. Increase in expression of the copper transporter ATP7A during platinum drug-based treatment is associated with poor survival in ovarian cancer patients. Clin Cancer Res. 2003; 9: 5853-9.

11. Blair BG, Larson CA, Safaei R, Howell SB. Copper transporter 2 regulates the cellular accumulation and cytotoxicity of Cisplatin and Carboplatin. Clin Cancer Res. 2009; 15: 4312-21.

12. Kuo MT, Chen HH, Song IS, Savaraj N, Ishikawa T. The roles of copper transporters in cisplatin resistance. Cancer Metastasis Rev. 2007; 26: 71-83.

13. Zhang Y, Li M, Yao Q, Chen C. Roles and mechanisms of copper transporting ATPases in cancer pathogenesis. Med Sci Monit. 2009; 15: Ra1-5.
14. Gatti L, Beretta GL, Cossa G, Zunino F, Perego P. ABC transporters as potential targets for modulation of drug resistance. Mini Rev Med Chem. 2009; 9: 1102-12.

15. Brambila-Tapia AJ. MDR1 (ABCB1) polymorphisms: functional effects and clinical implications. Rev Invest Clin. 2013; 65: 445-54.

16. Wen J, Zheng B, Hu Y, et al. Establishment and biological analysis of the EC109/CDDP multidrug-resistant esophageal squamous cell carcinoma cell line. Oncol Rep. 2009; 22: 65-71.

17. Qiang F, Guangguo R, Yongtao H, Dandan D, Hong Y. Multidrug resistance in primary tumors and metastases in patients with esophageal squamous cell carcinoma. Pathol Oncol Res. 2013; 19: 641-8.

18. Albertella MR, Green CM, Lehmann AR, O'Connor MJ. A role for polymerase eta in the cellular tolerance to cisplatin-induced damage. Cancer Res. 2005; 65: 9799-806.

19. Safaei R, Katano K, Samimi G, et al. Cross-resistance to cisplatin in cells with acquired resistance to copper. Cancer Chemother Pharmacol. 2004; 53: 239-46.

20. Ishida S, Lee J, Thiele DJ, Herskowitz I. Uptake of the anticancer drug cisplatin mediated by the copper transporter Ctr1 in yeast and mammals. Proc Natl Acad Sci U S A. 2002; 99: 14298-302.

21. Song IS, Savaraj N, Siddik ZH, et al. Role of human copper transporter Ctr1 in the transport of platinum-based antitumor agents in cisplatin-sensitive and cisplatin-resistant cells. Mol Cancer Ther. 2004; 3: 1543-9.

22. Li ZH, Qiu MZ, Zeng ZL, et al. Copper-transporting P-type adenosine triphosphatase (ATP7A) is associated with platinum-resistance in non-small cell lung cancer (NSCLC). J Transl Med. 2012; 10: 21.

23. Jin $\mathrm{W}$, Scotto $\mathrm{KW}$, Hait WN, Yang JM. Involvement of CtBP1 in the transcriptional activation of the MDR1 gene in human multidrug resistant cancer cells. Biochem Pharmacol. 2007: 74: 851-9.

24. Nakagawa $\mathrm{T}$, Inoue $\mathrm{Y}, \mathrm{Kodama} \mathrm{H}$, et al. Expression of copper-transporting P-type adenosine triphosphatase (ATP7B) correlates with cisplatin resistance in human non-small cell lung cancer xenografts. Oncol Rep. 2008; 20: 265-70.

25. Sharp SY, Rogers PM, Kelland LR. Transport of cisplatin and bis-acetato-ammine-dichlorocyclohexylamine Platinum(IV) (JM216) in human ovarian carcinoma cell lines: identification of a plasma membrane protein associated with cisplatin resistance. Clin Cancer Res. 1995; 1: 981-9.

26. Kim HW, Chan Q, Afton SE, et al. Human macrophage ATP7A is localized in the trans-Golgi apparatus, controls intracellular copper levels, and mediates macrophage responses to dermal wounds. Inflammation. 2012; 35: 167-75.

27. Wosikowski K, Lamphere L, Unteregger G, et al. Preclinical antitumor activity of the oral platinum analog satraplatin. Cancer Chemother Pharmacol. 2007; 60: $589-600$

28. Goodman VL, Brewer GJ, Merajver SD. Control of copper status for cancer therapy. Curr Cancer Drug Targets. 2005; 5: 543-9.

29. Owatari S, Akune S, Komatsu M, et al. Copper-transporting P-type ATPase, ATP7A, confers multidrug resistance and its expression is related to resistance to SN-38 in clinical colon cancer. Cancer Res. 2007; 67: 4860-8.

30. Yoshizawa K, Nozaki S, Kitahara H, et al. Copper efflux transporter (ATP7B) contributes to the acquisition of cisplatin-resistance in human oral squamous cell lines. Oncol Rep. 2007; 18: 987-91.

31. Holzer AK, Manorek GH, Howell SB. Contribution of the major copper influx transporter CTR1 to the cellular accumulation of cisplatin, carboplatin, and oxaliplatin. Mol Pharmacol. 2006; 70: 1390-4

32. Katano K, Kondo A, Safaei R, et al. Acquisition of resistance to cisplatin is accompanied by changes in the cellular pharmacology of copper. Cancer Res. 2002; 62: 6559-65.

33. Katano K, Safaei R, Samimi G, Holzer A, Rochdi M, Howell SB. The copper export pump ATP7B modulates the cellular pharmacology of carboplatin in ovarian carcinoma cells. Mol Pharmacol. 2003; 64: 466-73.

34. Samimi G, Safaei R, Katano K, et al. Increased expression of the copper efflux transporter ATP7A mediates resistance to cisplatin, carboplatin, and oxaliplatin in ovarian cancer cells. Clin Cancer Res. 2004; 10: 4661-9.

35. Plasencia C, Martinez-Balibrea E, Martinez-Cardus A, Quinn DI, Abad A, Neamati N. Expression analysis of genes involved in oxaliplatin response and development of oxaliplatin-resistant HT29 colon cancer cells. Int J Oncol. 2006; 29: 225-35.

36. Kitada N, Takara K, Minegaki $\mathrm{T}$, et al. Factors affecting sensitivity to antitumor platinum derivatives of human colorectal tumor cell lines. Cancer Chemother Pharmacol. 2008; 62: 577-84.

37. Mangala LS, Zuzel V, Schmandt R, et al. Therapeutic Targeting of ATP7B in Ovarian Carcinoma. Clin Cancer Res. 2009; 15: 3770-80.

38. Leonhardt K, Gebhardt R, Mossner J, Lutsenko S, Huster D. Functional interactions of $\mathrm{Cu}$-ATPase ATP7B with cisplatin and the role of ATP7B in the resistance of cells to the drug. J Biol Chem. 2009; 284: 7793-802. 